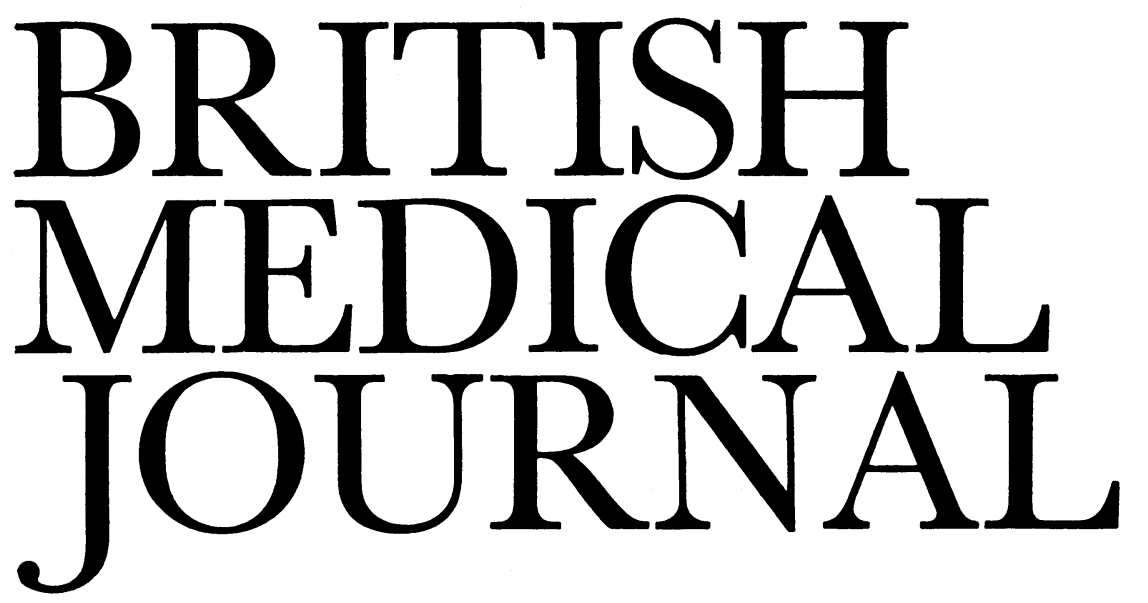

LONDON, SATURDAY 24 MARCH 1979

\title{
Leave no stone unturned
}

Exploration of the common bile duct is still a far from satisfactory operation. About 100000 such procedures are done every year in the United States alone, and in at least $10 \%$ of these explorations ${ }^{1}$ stones will be left behind; in a further, smaller but unknown, number of patients stones will form again. Nevertheless, considerable progress has been made in developing techniques for preventing and treating overlooked and recurrent common duct stones.

To avoid overlooking stones in the common bile duct the surgeon must, firstly, recognise all ducts that contain stones and explore them; secondly, he must extract all stones from the ducts explored; and, finally, he needs to recognise that small percentage of patients in whom stones are likely to form again and to do something to prevent this.

Until 15 or 20 years ago the decision to explore the common duct was made on clinical criteria. The absolute indications were the presence of jaundice, a dilated biliary tree, or a palpable stone, and the relative ones included the presence of multiple small stones, a history of jaundice, or a history of pancreatitis. This policy has changed since operative cholangiography has become routine, for now a surgeon can expect routinely to get $x$-ray films of good quality to show whether there are any of the abnormalities which require exploration of the common duct-namely, stones within the duct system, dilatation of the duct system, or a failure of contrast to flow readily into the duodenum.

The use of operative cholangiography has, then, meant that fewer ducts are being explored and a much higher proportion are yielding stones. ${ }^{2}$ Some surgeons have claimed that manometry of the bile ducts is as accurate, but this technique has not found general acceptance and has the disadvantage that there is no permanent visual record of the common duct for future reference.

The actual exploration of the duct requires painstakingly careful technique. Adequate exposure is essential, and this means complete mobilisation of the second part of the duodenum (Kocher's manoeuvre). The duct is gently explored with stone forceps and irrigated with saline through fine catheters. A fine balloon catheter is useful for extracting stones from the liver or from the lower end of the duct. The forceful use of dilators or other metal instruments is contraindicated, and if a stone is firmly impacted at the lower end of the duct the duodenum should be opened and the ampulla incised to allow it to be extracted without undue force. In a few patients the biliary system is packed with small stones, and complete clearance of the intrahepatic duct system is a physical impossibility; in them an additional operation for drainage of the duct may allow the stones to pass spontaneously.

Complete clearance of the duct system must be checked by postexploratory cholangiography or by choledochoscopy. Modern choledochoscopes give excellent views of the biliary tree and are simple to use. The busy surgeon may be tempted to omit the postexploratory check, but if he does so there will inevitably be patients in whom stones are overlooked. An obsessional insistence on thorough technique is vital for consistent results.

Before closing the bile duct the surgeon should consider whether the patient shows any of the features associated with recurrent formation of duct stones: these include the presence of biliary mud, papillary stenosis, multiple intrahepatic stones, or a grossly dilated bile duct. An additional procedure to drain the duct will prevent recurrent stones in such patients. A sphincteroplasty is the usual operation for patients with normalsized or only moderately dilated ducts, ${ }^{3}$ whereas those with grossly dilated (that is, a greater diameter than $18 \mathrm{~mm}$ ) ducts are probably best treated by choledochoduodenostomy. ${ }^{4}$

Most surgeons close the bile duct over a $\mathrm{T}$ tube. In certain circumstances primary closure of the duct is safe, but the procedure is rarely used. Use of a $T$ tube is safe, and it allows further radiological examination should this prove necessary. A further, more compelling argument for the routine use of $\mathrm{T}$ tube is that, with modern flexible instruments, any retained stones may be extracted simply enough through the $\mathrm{T}$ tube track-provided that the surgeon has used a No 12 or 14 French size $T$ tube, which leaves a track large enough to allow easy introduction of the stone extractor. The success rate of this procedure is high, over $95 \%$ in two recent series ${ }^{56}$ of 380 and 1086 patients - and the large numbers of patients show how frequent the problem must be. Even so, most of the retained stones in these patients resulted from a poor standard of operative cholangiography or a failure to carry out a postexploratory check.

When stones form again months or years after the primary operation further surgery used to be needed, but reoperation may now be avoided: the advance in endoscopic techniques has allowed endoscopic papillotomy and extraction of stones from the common duct. The technique requires considerable skill, but again the success rate is over $90 \%$. Though 
complications such as cholangitis, bleeding, stone impaction, and retroperitoneal perforation occur, the mortality rate in a series $^{7}$ of 562 patients (many of whom were poor operative risks) was only $1 \%$. This degree of safety and effectiveness would be difficult to match in a comparable series of reoperations on the common bile duct. Though we do not know the long-term effects of the papillotomy-and theoretically the papilla could stenose and cause later trouble-we have no evidence that stenosis occurs.

Surgeons have no reason to be complacent about the results of exploration of the bile ducts. The incidence of overlooked stones and stones forming again is neither acceptable nor inevitable. Nevertheless, with the careful use of radiology and endoscopy, combined with the judicious use of duct drainage procedures, the results will surely improve.

1 Orloff, M J, World fournal of Surgery, 1978, 2, 403.

${ }^{2}$ Kakos, G S, et al, Archives of Surgery, 1972, 104, 484

3 Jones, S A, Surgical Clinics of North America, 1973, 53, 1123.

4 Madden, J L, et al, American fournal of Surgery, 1970, 119, 45.

${ }^{5}$ Burhenne, H J, World Fournal of Surgery, 1978, 2, 439.

${ }^{6}$ Mazzariello, R M, World fournal of Surgery, 1978, 2, 447.

7 Safrany, L, World fournal of Surgery, 1978, 2, 457.

\section{Future provision of anaesthetic services}

\begin{abstract}
"There is likely to be a shortage of consultant candidates for some years to come," said the DHSS in comment ${ }^{1}$ on the prospects for anaesthetics in its latest set of data on staffing numbers and "fields of recruitment" in the hospital servicealready over a year out of date. Some consultant posts are certainly vacant at present, not only in less attractive nonteaching hospitals but also in the larger centres. The demands of surgeons, gynaecologists, and others for more operating time seem relentless and anaesthetists nowadays make important contributions to the care of patients outside the operating theatre. The number of anaesthetists in England and Wales has increased by over half in the last 10 years, and far more new consultants were appointed, even in the slow-growth year up to 30 September 1977, than in any other specialty. Hence we should not be surprised by the relative shortages of good anaesthetic recruits and trainees.
\end{abstract}

At present, senior registrars in anaesthetics do not seem to be hanging on to their financially rewarding posts rather than applying for consultant appointments at the right time, though more are completing a full three years of higher professional training than in the past. Mature senior registrars still have plenty of consultant posts to choose from. The numbers emigrating have always been difficult to assess, since reliable up-to-date figures are impossible to obtain. The General Medical Council's data show that the number of specialist certificates issued for working in the EEC has been much higher in anaesthetics than any other specialty; we do not know precisely what these figures mean, but we know that many British anaesthetists are working, either temporarily or permanently, in various Western European countries. British anaesthesia has high international prestige, and it is not only in the United Kingdom that it rates as a shortage specialty.

Though most anaesthetists readily admit that the details of the subject are for postgraduate study, there is still plenty to interest the medical student in the way of applied physiology and pharmacology, and practical experience in intubation, venepuncture, and resuscitation. Many medical schools have well-planned courses. ${ }^{23}$ As a first choice of career at the preregistration stage anaesthetics appears to be gaining in popularity. Applicants for senior house officer and registrar posts have improved in both number and quality in recent months, and anyone who now obtains a good registrar post in anaesthetics without the primary FFARCS is lucky. For senior registrars the change is even more noticeable, and regions where two or three years ago considerable numbers of such posts remained unfilled now face the unusual embarrassment of having to turn away good applicants to make a short list of manageable size. Interest has also risen in academic posts at the same level.

Both general practitioners and medical assistants contribute greatly to anaesthetic services. Any rational future policy should maintain this contribution under adequate control and supervision-but without jeopardy to patient safety in an increasingly complex and demanding specialty. ${ }^{4}$ Trained help is badly needed, but the scheme for operating department assistants (ODAs) has not provided the kind of career in relation to anaesthetics that many would hope to see. ${ }^{5}$ Nurses also have a valuable part to play, but not as frank substitutes for medical specialists. ${ }^{6}$ The Joint Board of Clinical Nursing Studies has already approved two anaesthetic courses; and the employment of well-trained nurses or technicians, with more general help from orderlies, would appeal to many anaesthetists, enabling them to provide better care and a wider range of services.

Now that recruitment in the specialty has become more favourable it is all the more important that the current increase in senior registrar establishment should be continued, with a proportionate increase in equivalent academic posts. Wherever possible the consultant establishment should be raised. The Central Manpower Committee has recently approved only 16 new consultant posts for 1979. There is obvious logic in not approving additional posts while existing posts remain unfilled, but is it not worth trying a more opportunist approach with encouragement to fill those posts that are attractive? While such a policy might seem to exacerbate inequalities both within and between regions it could pay off handsomely in the long term; for as numbers of eligible senior registrars rise there must be a natural movement towards the remaining consultant posts-provided that these can compete in attractiveness with opportunities abroad.

The new consultant contract may help the non-teaching hospitals in offering more money to those anaesthetists willing to work hard, but much more will often depend on the nature of the work. Most anaesthetists outside the teaching centres have absurdly little time to engage in obstetric epidural services and the more general management of pain or in intensive therapy. This kind of work would increase the attractiveness of posts to many applicants and bring benefits to the community. Obstetricians and surgeons are themselves becoming increasingly aware of the inadequacy of the service that their anaesthetists can provide in comparison with what is done in the major teaching centres. These feelings should be voiced more often, so supporting anaesthetists' pressures for wider job descriptions for consultant posts.

All those responsible for manpower policies must help by taking an imaginative view of the future of the specialty. Anaesthetists do not demand new buildings and other costly facilities for their work, nor do they have retinues of housemen, nurses, and other supporting staff. In relation to the cost, there would be enormous benefits from allowing the anaesthetic 